\title{
Postsurgical Stage III Hepatoblastoma
}

National Cancer Institute

\section{Source}

National Cancer Institute. Postsurgical Stage III Hepatoblastoma. NCI Thesaurus. Code C7144.

No distant metastases, tumor unresectable or resected with gross residual tumor, or positive lymph nodes. (from PDQ 2004) 